\title{
THE DISTANCE BETWEEN THE DIAFRAGM AND THE ORIGIN OF THE COLLATERAL BRANCHES OF THE ABDOMINAL AORTA
}

\section{Bardas Anamaria1, Bulbuc Ionut', Bordei Petru'}

${ }^{1}$ Faculty of Medicine, University "Ovidius" of Constanta

Petru Bordei

Faculty of Medicine, Univeristy ,, Ovidius " of Constanta, Universitatii Alee No. 1, Campus B, Constanta, Romania email:bordei@anatomie.ro phone: +40241605008

\section{ABSTRACT}

The Abdominal Aorta represents the terminal portion or the fourth portion of the artery, continuing the diaphragmatic portion, stretching from the aortic hiatus (at the level of the twelfth thoracic vertebra) up to the fourth lumbar vertebra, the level at which ends by bifurcation in the two common iliac artery, left and right.

The survey was carried out on the computed tomography angiography's executed on a computer tomography GE LightSpeed 16 slice CT in Medimar Imagistic Clinic located in the County Clinical Emergency Hospital "Sf. Andrei" Constanta, on healthy subjects and on the basis of sex.

The distance between the origins of the collateral branches of the aorta are highly variable, causing differences in relation to sex, generally being higher in male, exceptions being due to the fact that these distances are proportional with the morphological type of the individual in question. Frequently, the maximum and minimum values of the distances have not been encountered only in one event. Like other morfometric data, the distances between the collateral arteries of the abdominal aorta firstly depend on the number of cases which it has been worked, which explains the differences between authors who are working on the same grounds and at close intervals of time, but differs on the number of cases which are working.

Keywords: abdominal aorta, computet tomography, collateral branches

\section{Introduction}

After (1), The Abdominal Aorta represents the terminal portion or the fourth portion of the artery, continuing the diaphragmatic portion, stretching from the aortic hiatus (at the level of the twelfth thoracic vertebra) up to the fourth lumbar vertebra, the level at which ends by bifurcation in the two common iliac artery, left and right.

The aortic bifurcation is prevertebral and median, after some authors being slightly to the left of the midline. In the majority of cases, it corresponds to the third lower part of the fourth lumbar vertebra ( $70 \%$ of cases) and more rarely, the upper half of the fifth lumbar vertebra (lower bifurcation, infraduodenal) or the third upper part of the fourth lumbar vertebra (high bifurcation, retroduodenala). The aortic bifurcation is always located a few $\mathrm{cm}$ above the promontory ( 6 centimeters on average) and in general in an upper level than the inferior vena cava. From the beginning and through the end its caliber does not diminish significantly, against the voluminous branches which it issues, which denotes that the abdominal aorta is both a passage way and an arterial trunk. But the abdominal aorta may present pathological widenings,anevrisms, frequently lumbar, whose therapy requires a good knowledge of the anatomy of the arteries 
(morfometry, the distribution of the collateral branches, the structure of the arterial wall).

\section{Summary}

The distance between the origin of the abdominal aorta's branches has been determined on a computer tomography GE LightSpeed 16 slice CT on healthy subjects and on the basis of sex. The celiac trunk has its origin at a distance of $5,1-42 \mathrm{~mm}$ from the diaphragm, and the distance between the diafragm and the origin of the superior mezenteric artery has been found between 31,6-64,1 $\mathrm{mm}$. The distance between the aortic diafragm and the origin of the left renal arteries was between 30,4-76.8 $\mathrm{mm}$ and between $28,4-76,7 \mathrm{~mm}$ for the right renal artery. The distance between the diafragm and the origin of the inferior mesenteric artery was $107,4-153 \mathrm{~mm}$, between the origin of the celiac trunk and the inferior mesenteric artery we found a distance between 8,4-35.8 $\mathrm{mm}$, and between the celiac trunk and the origin of the left renal artery the distance was 22,5-40.3 mm. Between the celiac trunk and the origin of the right renal artery we found a distance of $21,8-43,7 \mathrm{~mm}$, and between the celiac trunk and the origin of the inferior mesenteric artery $56,2-100 \mathrm{~mm}$. Between the celiac trunk and the aortic bifurcation it was a distance of 127,3-148.6 $\mathrm{mm}$, the distance between the superior mesenteric artery and the origin of the left renal artery 9,4-18mm.The distance between the superior mesenteric artery and the right renal artery was $6,8-16.6 \mathrm{~mm}$, the distance between the superior and the inferior mesenteric artery was 40,4-84.6 $\mathrm{mm}$. The distance between the aortic origin of the left renal artery and the inferior mesenteric artery was 48,5-67 and the distance between the aortic origin of the right renal artery and the inferior mesenteric artery was $59,3-113 \mathrm{~mm}$.

\section{Methods and material}

The survey was carried out on the computed tomography angiography's executed on a computer tomography GE LightSpeed 16 slice CT in Medimar Imagistic Clinic located in the County Clinical Emergency Hospital
"Sf. Andrei" Constanta, on healthy subjects and on the basis of sex. There were measured the distances between the main collateral branches of the abdominal aorta, the morfometry, that has a particular importance in the surgical interventions at this level. The number of cases which were determined, the measurements taken are characteristic of each mark followed, being made on the basis of sex.

\section{Results}

The distance between the celiac trunk in relation to the diafragm I found it between $5,1-42 \mathrm{~mm}$, in the female gender between 5,1$42 \mathrm{~mm}$, and in the male between $11,0-41 \mathrm{~mm}$. The distance between the diaphragm and the origin of the superior mesenteric artery I found it between $31,6-64,1 \mathrm{~mm}$, in female being 31,6-56,7 mm, and male between $31,6-64,1 \mathrm{~mm}$. The distance between the aortic diafragm and the origin of the left renal artery was found between 30,4-76.8 $\mathrm{mm}$, in female $30,4 \mathrm{~mm}$ and male between $42,2-$ $76.8 \mathrm{~mm}$.

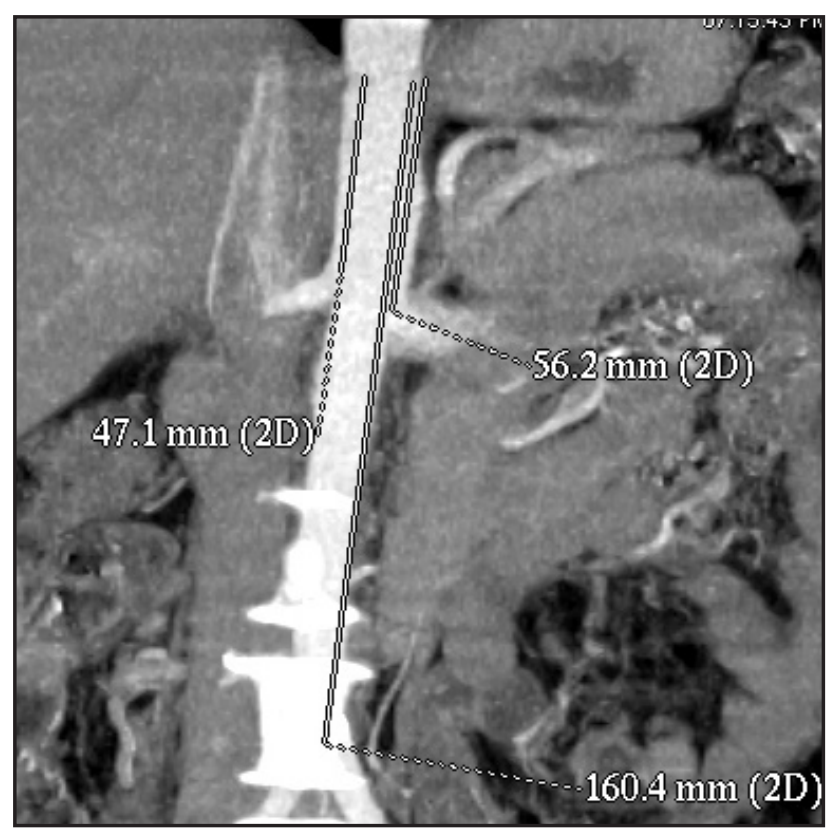

Figure 1 External distance between the diaphragm and the renal arteries is 47,1 $\mathrm{mm}$ for the right one and 56,2 $\mathrm{mm}$ for the left one; distance diaphragm-end of the aorta is 160,4 $\mathrm{mm}$ (female).

The distance between the aortic diafragm and the origin of the right renal artery was between 28,4-76,7 mm, in female 28,4-69.4 mm, and male within $42,8-76,7 \mathrm{~mm}$. The distance 
between the diafragm and the origin of the lower mesenteric artery I found it within 107,4-153mm, in female being 100,4-153,2 $\mathrm{mm}$, and male between 118,8-153,7 $\mathrm{mm}$. The distance between the aortic diafragm and the aortic bifurcation I found it between $135,3-183 \mathrm{~mm}$, in female being between135,3-160.4 mm, and male within 139,2$183 \mathrm{~mm}$.

Between the origins of the celiac trunk and inferior mesenteric artery it was a distance between 8,4-35.8 $\mathrm{mm}$, in female being 15,9-17.5 $\mathrm{mm}$, and in male $8,4-35.8 \mathrm{~mm}$.

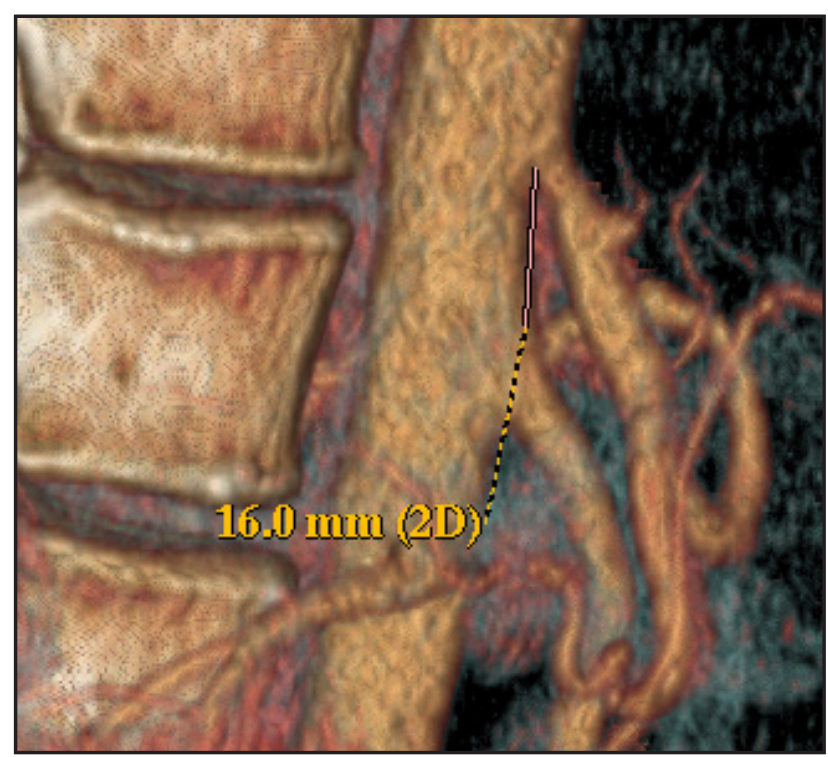

Figure 2 External distance between the celiac trunk and the superior mesenteric artery is 16,0 $\mathrm{mm}$ (female).

The distance between the celiac trunk and the origin of the left renal artery was found 22,5$40.3 \mathrm{~mm}$, in female being $24,5-40.3 \mathrm{~mm}$, and male within $22,5-37.3 \mathrm{~mm}$. The distance between the celiac trunk and the origin of the right renal artery was $21,8-43,7 \mathrm{~mm}$, in female being $28,4-$ $36.9 \mathrm{~mm}$, and male the $21,8-43,7 \mathrm{~mm}$. Between the celiac trunk and the origin of the inferior mesenteric artery it was a distance of 56,2-100 $\mathrm{mm}$, for female gender being 77,1-98.3 $\mathrm{mm}$, and male gender between 56,2-100mm. Between the celiac trunk and the aortic bifurcation it was a distance of 127,3-148.6 mm, in female the distance being 127,3-133.9 $\mathrm{mm}$, and male between 127,3-133.9 $\mathrm{mm}$. The distance between the superior mesenteric artery and the origin of the left renal artery was within 9,4-18 0,2 mm, in female being 11,1-16.6 mm, and male of 9,4-18 $0,2 \mathrm{~mm}$.

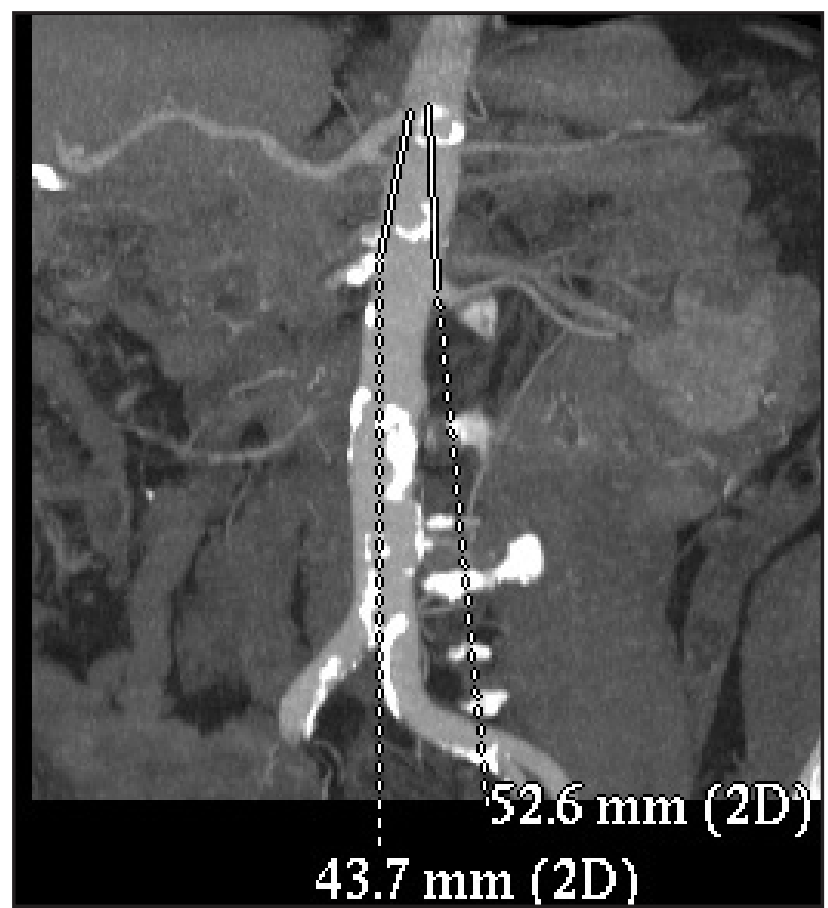

Figure 3 External distance between the celiac trunk and the renal arteries is 43,7 $\mathrm{mm}$ right side and 52,6 $\mathrm{mm}$ left side (male).

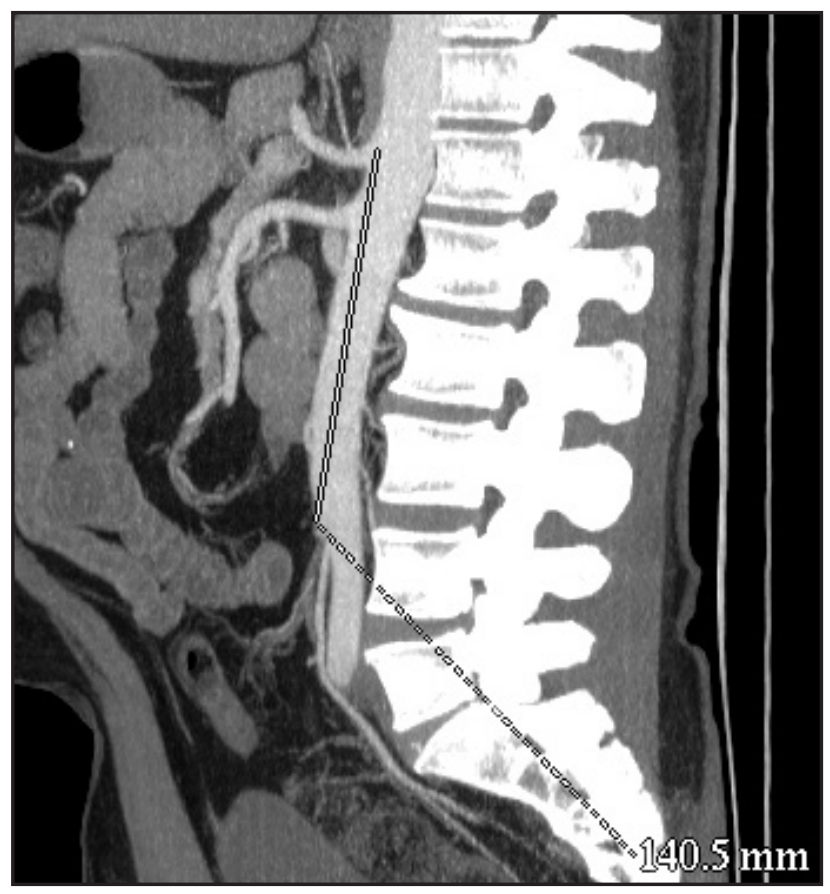

Figure 4 External distance between the celiac trunk and the inferior mesenteric artery is 140,5 $\mathrm{mm}$ (male).

The distance between the superior and inferior mesenteric artery was 40,4-84.6 mm, in female being $40,4-84.6 \mathrm{~mm}$, and male to $53,3-80,7 \mathrm{~mm}$. The distance between the origin of the superior mesenteric artery and the aortic bifurcation was $98,5-119.6 \mathrm{~mm}$, in female being 98,5-116.8 mm, and male within 10,5,2-109.6 $\mathrm{mm}$. 


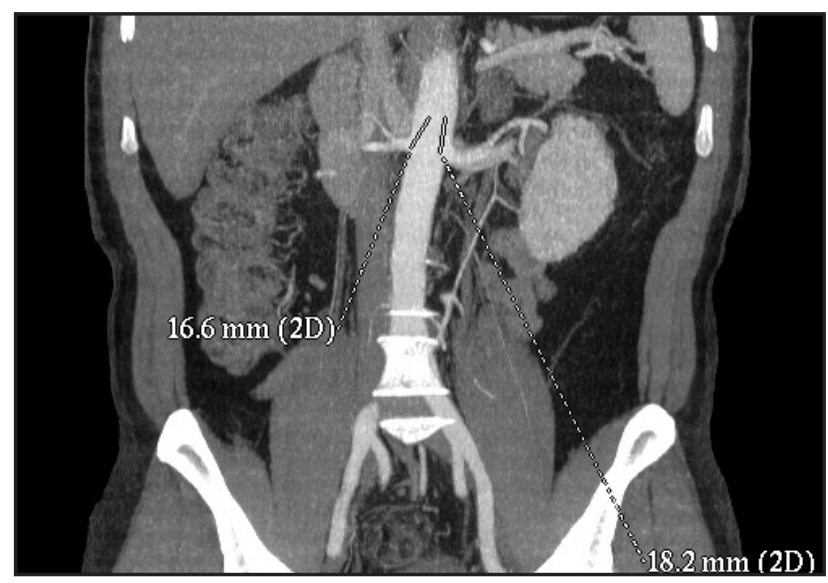

Figure 5 External distance between the superior mesenteric artery and renal arteries is $16.6 \mathrm{~mm}$ to 18.2 $\mathrm{mm}$ right and left, right renal artery originating above in the aorta (male).

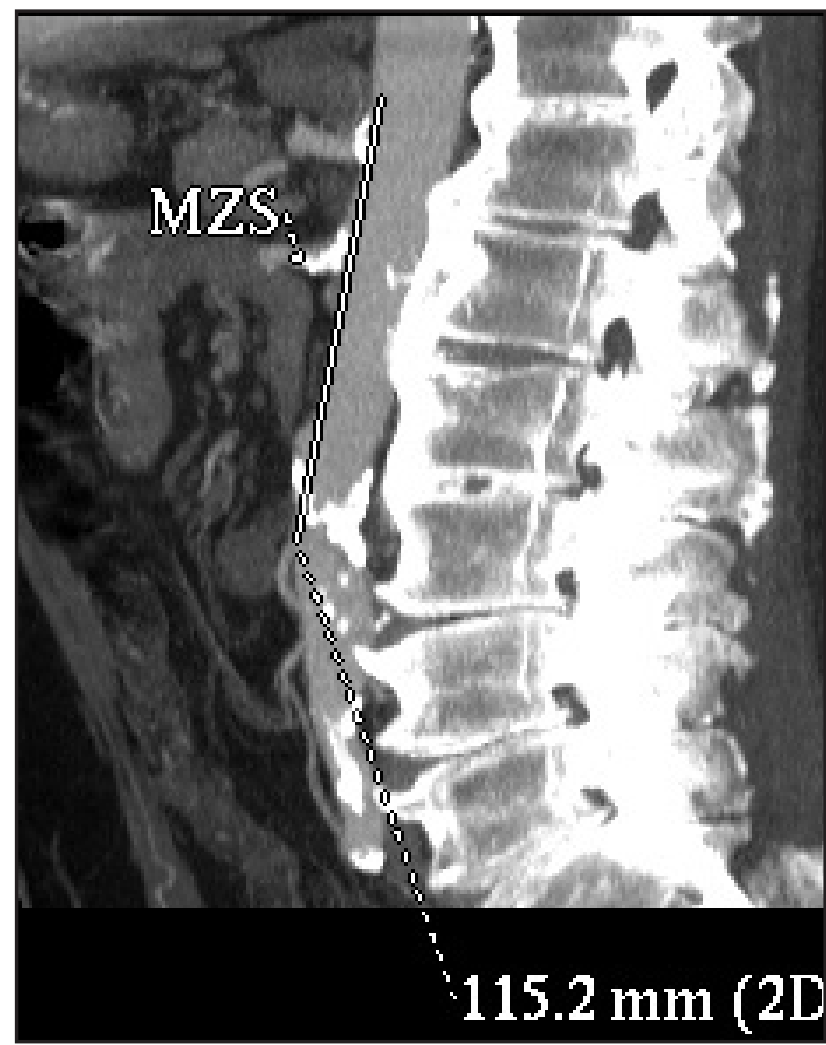

Figure 6 External distance between the superior mesenteric artery and inferior mesenteric artery 115,2 mm (male)

The distance between the aortic origin of the left renal artery and the inferior mesenteric artery was within $48,5-67,2 \mathrm{~mm}$, in female being 50,4-67,2 mm, and male within 48,5-54.9 mm. The distance between the left renal artery and the aortic bifurcation was 59,2-109 $\mathrm{mm}$, in female being 59,2-105 0,2 $\mathrm{mm}$, and male within 94,7$109,1 \mathrm{~mm}$. The distance between the right renal artery and the origin of the inferior mesenteric artery was found $59,3-113 \mathrm{~mm}$, in female being 59,3-113 70, and male of 107,3-110.6 $\mathrm{mm}$. The distance between the right renal artery and the aortic bifurcation was found between 59,3-113 $70 \mathrm{~mm}$, in female being $59,3-11370 \mathrm{~mm}$, and male between 107,8-110.6 mm.

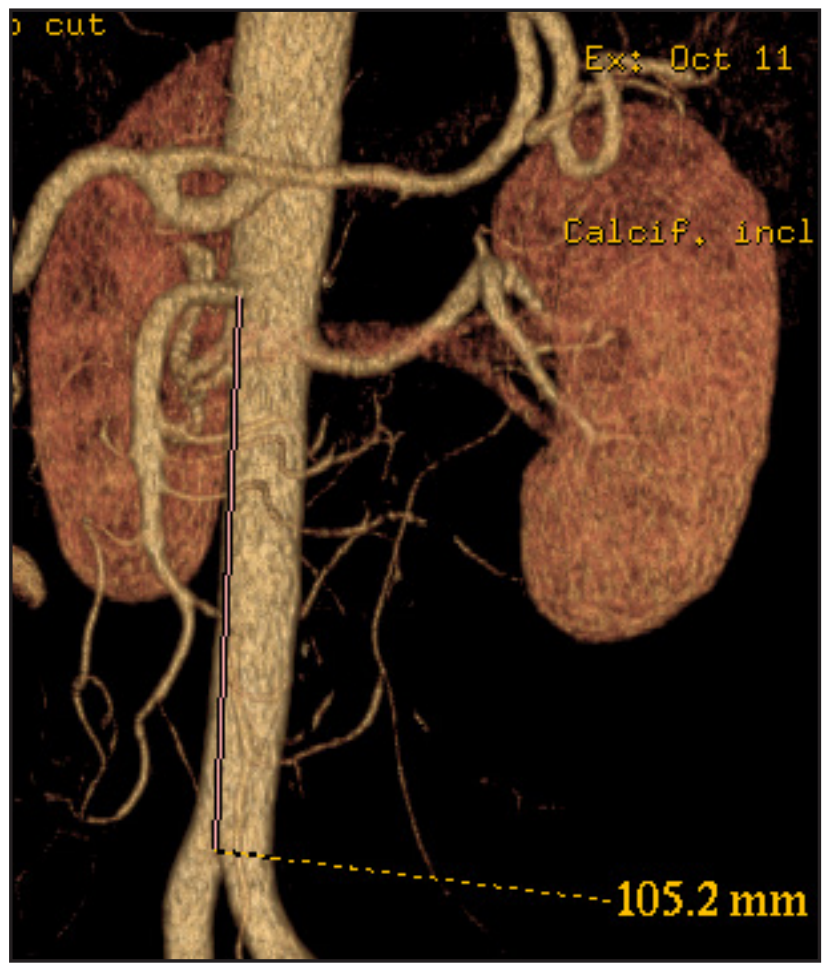

Figure 7 External distance between the superior mesenteric artery and the end of the aorta 105,2 $\mathrm{mm}$ (male).

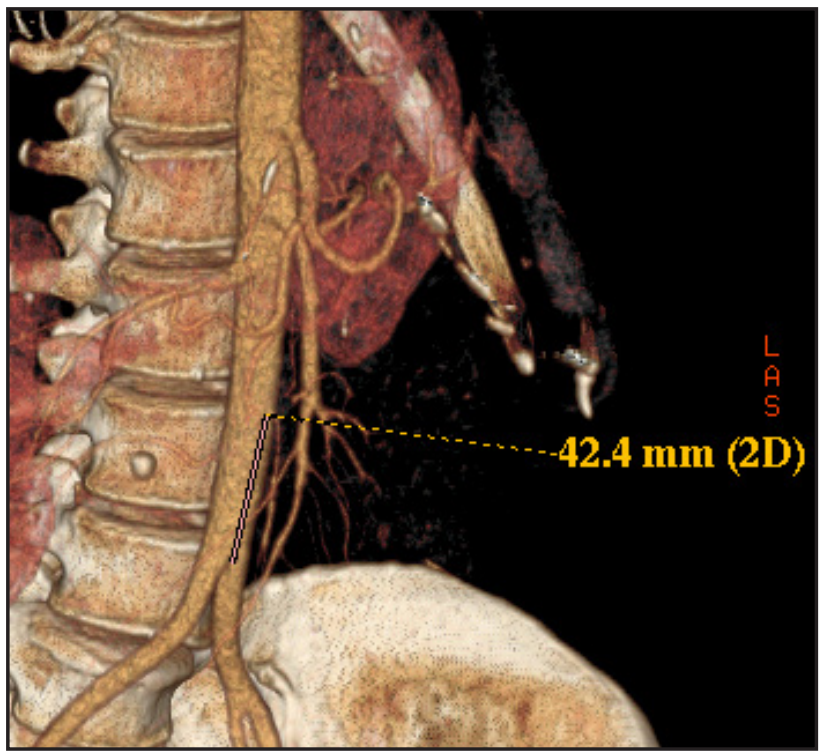

Figure 8 External distance between the inferior mesenteric artery and the end of the aorta is $42,4 \mathrm{~mm}$ (female). 


\section{Discussions}

Between the diafragm and the celiac trunk, the minimum distance was found in female gender, it was less than $1 \mathrm{~mm}$ and the maximum distance was in male, with $5.9 \mathrm{~mm}$. The minimum distance between the diafragm and the superior mesenteric artery was the same in both sexes (31,6 $\mathrm{mm})$, but the maximum distance was found in male gender with $29.4 \mathrm{~mm}$. The minimum distance between the diafragm and left renal artery was higher in female gender with 11,80 $\mathrm{mm}$ and maximum distance was greater in male with $6.8 \mathrm{~mm}$. The minimum distance between the diafragm and right renal artery was the same in both sexes $(14,40 \mathrm{~mm})$ and the maximum distance was higher in male with $7.3 \mathrm{~mm}$. Between the diaphragm and the inferior mesenteric artery there were both distances greater in male, the minimum being more than $18,8 \mathrm{~mm}$, and the maximum more than $5.0 \mathrm{~mm}$. The distances were also higher in male between the origin of the inferior mesenteric artery and the aortic bifurcation, the minimum distance being more than $2.0 \mathrm{~mm}$, and the maximum distance higher than $2.8 \mathrm{~mm}$. The minimum distance between the celiac trunk and the superior mesenteric artery in male was more than $7,6 \mathrm{~mm}$ in the case of minimum value, and $18.3 \mathrm{~mm}$ in the case of the maximum value. The distance between the celiac trunk and left renal artery were greater in female gender, the minimum $2.0 \mathrm{~mm}$, and the maximum $3.0 \mathrm{~mm}$.

The minimum distance between the celiac trunk and right renal artery has it's minimum value greater in female with $6.6 \mathrm{~mm}$, and the maximum distance was higher in male with 6.8 $\mathrm{mm}$. The distance between the origins of the celiac trunk and the inferior mesenteric artery have the minimum value greater in female with $20.9 \mathrm{~mm}$; and the maximum value in male with $1.9 \mathrm{~mm}$. The distance between the celiac trunk and the aortic bifurcation, has the minimum value greater in male with $1.5 \mathrm{~mm}$, and the maximum value also in male with $14.7 \mathrm{~mm}$. The distance between the superior mesenteric artery and the left renal artery was higher (with $1.7 \mathrm{~mm}$ ) in the female gender in the case of the minimum value, and the maximum value greater in male with $1.6 \mathrm{~mm}$.
The distance between the superior mesenteric artery and right renal artery, has higher values in male, the minimum is more than $1.6 \mathrm{~mm}$ and the maximum 1, $7 \mathrm{~mm}$. The distance between the superior and inferior mezenteric arteries, had the minimum values greater in male with 12.9 $\mathrm{mm}$ and the maximum values in female more than $4.1 \mathrm{~mm}$. The distance between the inferior mesenteric artery and the aortic bifurcation have the minimum and maximum values higher in male, the minimum value being of more than 2.0 $\mathrm{mm}$, the maximum more than $2.8 \mathrm{~mm}$.

We have found that the origin of the celiac trunk is located at an average distance of 24.98 $\mathrm{mm}$, while (2) places it immediately below the upper angle of the pillars of the diaphragm, (6) finds the origin of the celiac trunk slightly below the upper angle of the aortic hiatus of the diaphragm, for (1) the origin of the celiac trunk is located between the two diaphragmatic pillars, most commonly being at $15-20 \mathrm{~mm}$ below the middle of the pillar's arcade, above the superior mezenteric artery, and (7) locates the origin of the celiac trunk of at $1 \mathrm{~cm}$ below the front part of the aortic hiatus of the diafragm. The distance that exists between the origins of the celiac trunk and the superior mesenteric artery, we found an average of $18,92 \mathrm{~mm}$, for (2) the superior mesenteric artery has a fixed origin, under the celiac trunk and very close to him. Quoting Rio Branco, considers this distance should be of 1-3 $\mathrm{mm}$ (2), considers that the distance between the two arteries is 5,8-10 $\mathrm{mm}$ and can be between 10 $20 \mathrm{~mm}$ (2).For (1) the distance is $8-10 \mathrm{~mm}$, and (9) found this distance of $20 \mathrm{~mm}$. The majority of the authors consider the distance between the origins of the celiac trunk and the superior mesenteric artery as $10 \mathrm{~mm}:(3,45,7,10)$. $(11,12)$ finds that the distance between the celiac trunk and the superior mesenteric artery is 5,0-13.6 $\mathrm{mm}$, both values are smaller than those found by us, the minimum with $3,4 \mathrm{~mm}$ and the maximum with $22.2 \mathrm{~mm}$.(12) affirms that the average distance between the ostium of the celiac trunk and the superior mesenteric artery is $17.9 \mathrm{~mm}$. (13) finds that the distance between the celiac trunk and the left renal artery is an average of $33,2 \mathrm{~mm}$, and between the celiac trunk and the right renal artery is a distance of $30.0 \mathrm{~mm}$.

The unique renal arteries shall have the 
origin slightly below the origin of the superior mesenteric artery (7), we found that the distance between the superior mesenteric artery and the left renal artery has an average of $18,59 \mathrm{~mm}$, between the superior mesenteric artery and the right renal artery there is an average of $14.80 \mathrm{~mm}$, which shows that the right renal artery has its origin in the aorta frequently located above in comparison to the origin of the left renal artery. $(11,12)$ finds that the distance between the superior mesenteric artery and the right renal artery is $6,2-23,56 \mathrm{~mm}$, the minimum value being less than that found by us with $0.6 \mathrm{~mm}$, and the maximum value is greater than $6.9 \mathrm{~mm}$, the distance between the superior mesenteric artery and the left renal artery of $5,7-23.5 \mathrm{~mm}$, the minimum value being less than that found by us with $3.7 \mathrm{~mm}$, and the maximum value greater than $5.3 \mathrm{~mm}$. (13) finds that the distance between the superior mezenteric artery and the left renal artery is an average of $17,4 \mathrm{~mm}$, and between the celiac trunk and of the right renal artery is a distance of $13.9 \mathrm{~mm}$. The distance between the mezenteric arteries, superior and inferior, I found an average of $69,51 \mathrm{~mm}$. (11) finds that the distance between the upper and lower mezenteric arteries is 50,6$91,2 \mathrm{~mm}$, values higher than those found by us with the minimum $6.2 \mathrm{~mm}$ and $7.4 \mathrm{~mm}$ max. Between the inferior mesenteric artery and the aortic bifurcation I found an average of 39,43 $\mathrm{mm}$. After (1) this distance is approximately 70 $80 \mathrm{~mm}$ or the origin of the inferior mezenteric artery is located at $40-50 \mathrm{~mm}$ above the aortic bifurcation, and after (8) the inferior mesenteric artery has its origin in the aorta at 5-6 cm above the end of the aorta. After (4) and (5) the origin of the inferior mesenteric artery is $30-40 \mathrm{~mm}$ above aortic bifurcation.

\section{Conclusions}

The distance between the origins of the collateral branches of the aorta are highly variable, causing differences in relation to sex, generally being higher in male, exceptions being due to the fact that these distances are proportional with the morphological type of the individual in question. Frequently, the maximum and minimum values of the distances have not been encountered only in one event. Like other morfometric data,the distances between the collateral arteries of the abdominal aorta firstly depend on the number of cases which it has been worked, which explains the differences between authors who are working on the same grounds and at close intervals of time, but differs on the number of cases which are working. The knowledge of the distance between the visceral branches of the abdominal aorta is important in surgical interventions, for samplings, transplants or treatment of aortic anevrisms.

\section{References}

1. Paturet G. Traité d'anatomie humaine Tome III Fasc. I Appaareil circulatoire. Paris: Masson; 1958.

2. Testut L. Traité d'anatomie humaine. Le pericard et le coeur, Deuxiemè partie. Paris: Gaston Doin; 1924.

3. Rouviere H, Delmas A. Anatomie Humaine. Descriptive, topographique et fonctionelle. Tome 2. Tron. Paris: Masson; 1997.

4. Moore A L. Posterior abdominal wall and retroperitoneu,. In: Standring S, editor. Gray's Anatomy The anatomical basis of clinical practice. Edinborough: Elsevied Churchill Livingstone; 2005.

5. Kamina P. Aorte abdominale. In: Kamina $\mathrm{P}$, editor. Anatomie clinique Tome 3 Thorax Abdomen: Maloine; 2007.

6. Juskiewenski S, Guitaed J. Les reins et les ureteres. In: Chevrel J, editor. Anatomie clinique. Paris, Berlin, Heidelberg, New York, London, Tokyo, Hong Kong: SpringerVerlag; 1944.

7. Pillet $\mathrm{J}$ Aorte abdominale et ses branches. In: JP Chevrel, Anatomie clinique (1994). Le Tronc. Ed. Springer-Verlag, Paris, Berlin, Heidelberg, New York, Londres, Tokyo, Hong Kong, 421-439

8. Testut L. Traité d'Anatomie humaine. Livre IV. Angéiologie. Paris :Gaston Doin; 1924

9. Chevrel JP. Le jejuno-ileum. In: Chevrel JP, Anatomie clinique . Le Tronc. Paris: Springer-Verlag; 1994

10. Schünke M, Schulte E, Scumacher U, Voll M, Wesker K. Atlas d'Anatomie. Cou et organes internes. Paris: Maloine; 2005

11. NiscoveanuC.Morphologicalconsiderations, 
the territories of vascularisation and anatomical variants of the upper mezenteric artery. Doctoral thesis, Constanţa: University Ovidius of Constanta. 2016

12. Niscoveanu C, Bordei $P$, Baz $R$ Morphological characteristics of origin of superior arterial mesenteric trunk. ARS Medica Tomitana. 2016 Aug 1;22(3):145-52.
13. Ozan H, Alemdaroglu A, Sinav A, Gümüsalan Y. Location of the ostia of the renal arteries in the aorta. Surgical and Radiologic Anatomy. 1997 Jul 1;19(4):245-7.

14. Terminologia Anatomica. Federative committee on anatomical terminology. Stuttgard: Georg Thieme. 1998. 